\title{
The microstructure evolution of hydrogenated microcrystalline germanium promoted by power gradient method
}

\author{
Xinyu Wang, Jian Ni*, Chang Li, Xiaoxiang Sun, Zhenglong Li, Hongkun Cai, Juan Li, Jianjun \\ Zhang*
}

College of Electronic Information and Optical Engineering, Nankai University, Key Laboratory of Photo-electronics Thin Film Devices and Technique of Tianjin, Tianjin, 300071, China.

\section{ABSTRACT}

This paper studies the microstructure evolution of hydrogenated microcrystalline germanium ( $\mu \mathrm{c}-\mathrm{Ge}: \mathrm{H})$ thin films deposited by plasma enhanced chemical vapor deposition (PECVD). There is an amorphous incubation layer formed in the initial deposition stage of $\mu \mathrm{c}-\mathrm{Ge}: \mathrm{H}$ thin film. It is demonstrated that the thickness of incubation layer can be reduced by high hydrogen dilution and high discharge power method. However, at high hydrogen dilution, the deposition rate of $\mu \mathrm{c}-\mathrm{Ge}: \mathrm{H}$ appears a sharply decrease. Using a high discharge power can compensate the deposition rate decrease but lead to decrease of average grain size and appearance of micro-void in the $\mu \mathrm{c}-\mathrm{Ge}: \mathrm{H}$ thin film. In addition, by comparing two thickness groups of $\mu \mathrm{c}-\mathrm{Ge}: \mathrm{H}$ thin films deposited at different discharge powers, it is noticed that the evolution process relates to the formation of crystal nucleuses. Thus, a power gradient method is proposed to understand the mechanism of nucleation and crystal growth in the initial deposition process of $\mu \mathrm{c}-\mathrm{Ge}: \mathrm{H}$ films. Finally, by power gradient method, the incubation layer thickness of $\mu \mathrm{c}-\mathrm{Ge}: \mathrm{H}$ thin films has been decreased to less than $6 \mathrm{~nm}$. Moreover, Raman scattering spectra shows a $38 \mathrm{~nm} \mu \mathrm{c}-\mathrm{Ge}: \mathrm{H}$ film has a crystal fraction

\footnotetext{
* Corresponding author at: College of Electronic Information and Optical Engineering, Nankai University, Tianjin 300071, China.

E-mail address: elsevier_jianni@163.com (J. Ni), jjzhang@nankai.edu.cn (J. Zhang)
} 
$\left(X_{C}\right)$ of $62.4 \%$. Meanwhile, the mobility of TFT devices shows the improved electrical property of $\mu c-G e: H$ film deposited by power gradient method.

KEYWORDS: B2. Hydrogenated microcrystalline germanium; A3. Plasma enhanced chemical vapor deposition; A3. Power gradient method; A1. Nucleation; A1. Incubation layer; B3. Thin film transistors

\section{Introduction}

Hydrogenated microcrystalline germanium ( $\mu \mathrm{c}-\mathrm{Ge}: \mathrm{H})$ thin films prepared by plasma enhanced chemical vapor deposition (PECVD) have a high optical absorption coefficient and a narrow optical gap closing to $0.66 \mathrm{eV}[1,2]$. This promises $\mu \mathrm{c}-\mathrm{Ge}: \mathrm{H}$ thin films can be widely used in narrow band gap photovoltaic devices and thin film transistors (TFTs) [3,4]. It was reported that the growth mechanism of $\mu \mathrm{c}-\mathrm{Ge}: \mathrm{H}$ thin films is basically similar to the hydrogenated microcrystalline silicon ( $\mu \mathrm{c}-\mathrm{Si}: \mathrm{H})$ which has been extensively studied [5-9]. In the initial growth process, at first, a layer of amorphous germanium (a-Ge:H), called incubation layer, appears on substrate, and then crystalline grains appear and grow up. There is a region that amorphous structure gradually evolves into microcrystalline structure [10-12]. However, in this region, a thick incubation layer deteriorates all film and device performance. In the application of solar cells, since photo-generated carriers are transported along the growth direction in intrinsic layer, defects in incubation layer increase carrier recombination rate. Furthermore, when the film is thin, a high amorphous content causes electrical properties deteriorate and lead to TFT performance decrease.

In order to reduce incubation layer thickness and promote microstructure evolution, many methods have been adopted in $\mu \mathrm{c}-\mathrm{Si}: \mathrm{H}$ thin films studies, like high hydrogen dilution and two step growth methods [13-16]. A high crystalline volume fraction of $\mu \mathrm{c}-\mathrm{Si}: \mathrm{H}$ films was obtained by 
using high hydrogen dilution, however, it caused a sharply decrease of the deposition rate simultaneously $[17,18]$. To further improve the crystalline fraction $\left(X_{C}\right)$, two step deposition method [15] or named hydrogen plasma treatment method was studied. By using a film treated by $\mathrm{H}_{2}$ plasma for few minutes as a seed layer, the film following deposited on this layer has a high crystalline fraction.

In this paper, we study the properties of initial deposition stage and the microstructure evolution of $\mu \mathrm{c}-\mathrm{Ge}: \mathrm{H}$ films. At first, we show that the same as $\mu \mathrm{c}-\mathrm{Si}: \mathrm{H}$, the high hydrogen dilution method is an effective method for reducing the incubation layer thickness of $\mu c-G e: H$ thin films. And then, by comparing two thickness groups of $\mu \mathrm{c}-\mathrm{Ge}: \mathrm{H}$ films deposited under different discharge powers, we find that a higher power can further promote the microstructure evolution and compensate the decrease of deposition rate caused by high hydrogen dilution. We illustrate the evolution of crystal fraction and surface morphology with the thickness increase of $\mu \mathrm{c}-\mathrm{Ge}: \mathrm{H}$ films. Finally, a power gradient method is proposed to understand the nucleation mechanism. Furthermore, we find this method is helpful for further reducing the thickness of incubation layer and controlling crystalline fraction and average grain size to achieve a homogeneous distribution of the crystal grains. Meanwhile, TFTs are used to evaluating the electrical properties of $\mu \mathrm{c}-\mathrm{Ge}: \mathrm{H}$ films since the mobility can be extracted from current-voltage characteristics.

\section{Experimental details}

All $\mu \mathrm{c}-\mathrm{Ge}: \mathrm{H}$ samples were deposited on glass substrates (Corning 7059) in a six-chamber-cluster RF-PECVD system using a $\mathrm{GeH}_{4}$ and $\mathrm{H}_{2}$ gas mixture, at a total gas flow of $200 \mathrm{sccm}$, a chamber pressure of 1 Torr and a temperature of $260{ }^{\circ} \mathrm{C}$. The crystalline volume fraction and the microstructure evolution of $\mu \mathrm{c}-\mathrm{Ge}: \mathrm{H}$ films were investigated by Raman scattering 
spectroscopy, using an InVia Renishaw Raman system with a He-Ne laser excitation at $514.5 \mathrm{~nm}$. The structural properties of $\mu \mathrm{c}-\mathrm{Ge}: \mathrm{H}$ thin films were observed by transmission electron microscope (TEM). Atomic force microscopy (AFM Seiko SPA-400) was carried out to observe the surface morphology. X-ray diffraction measurements was carried out using a Philips X'pert Pro diffractometer with $\mathrm{Cu}-\mathrm{K} \alpha$ radiation at $45 \mathrm{kV}$ and $40 \mathrm{~mA}$. The electrical performance of the TFT devices was measured using a Keysight Technologies B1500A Semiconductor Device Analyzer. All devices were tested in air at room temperature.

The $\mu \mathrm{c}-\mathrm{Ge}: H$ samples (R199, R249, R499 and R999) prepared at different hydrogen dilution ratios $\left(R_{H}=\left[\mathrm{H}_{2}\right] /\left[\mathrm{GeH}_{4}\right]\right)$ have a same thickness of $25 \mathrm{~nm}$ by controlling the deposition time. The groups of P05 and P35 were prepared at the RF discharge power of $5 \mathrm{~W}$ and $35 \mathrm{~W}$ respectively, and $R_{H}=999$. Furthermore, another group (G1-G4) was prepared by the power gradient method. At first, a $3 \mathrm{~nm}$ initial layer was deposited at $35 \mathrm{~W}$ discharge power. And then, the power was turned down to $5 \mathrm{~W}$ in a short time $(<5 \mathrm{~s})$ and kept plasma discharge continuous. At $5 \mathrm{~W}$ discharge power, the initial layer with crystal nucleuses followed deposition of different time. The TFT samples were prepared using $5 \mathrm{~W}, 35 \mathrm{~W}$ and power gradient method, to evaluate the electrical properties. The thickness of channel layer is $20 \mathrm{~nm}$ and the thickness of gate dielectric layer $\left(\mathrm{SiO}_{2}\right)$ is $270 \mathrm{~nm}$.

\section{Results and discussions}

\subsection{Effect of high hydrogen dilution}

Fig. 1 shows the Raman spectra and TEM measurements of the group prepared under different hydrogen dilution conditions. Table 1 lists the deposition parameters. The Raman spectra shown in Fig. 1(a) indicates that with $R_{H}$ increasing, there is a transition from amorphous to 
microcrystalline phase. In Fig. 1(a), the crystalline fraction $\left(X_{C}\right)$ is defined as the peak intensity ratio $X_{C}=\left(I_{300}+I_{295}\right) /\left(\mathrm{I}_{300}+I_{295}+I_{275}\right)$ [19]. It has been reported that using different laser wavelength, the penetration depth of Raman is different, and the penetration depth related to the absorption coefficient [20]. For the Ge films, the effective detection depth of $514 \mathrm{~nm}$ Raman laser is about $10 \mathrm{~nm}$.

For the $\mu \mathrm{c}-\mathrm{Ge}: \mathrm{H}$ films, with the same film thickness of $25 \mathrm{~nm}$, a higher Raman crystalline fraction means the initial amorphous layer, or named incubation layer, is thinner. If crystal grains just form on the film surface, the thickness of incubation layer will be equal to the film thickness. It is about $25 \mathrm{~nm}$ for the incubation layer thickness of sample R249, but for sample R199 thickness is larger than $25 \mathrm{~nm}$. Therefore, high hydrogen dilution is an effective method for decreasing amorphous incubation layer thickness and promoting microstructure evolution of $\mu \mathrm{c}-\mathrm{Ge}: \mathrm{H}$ films at the same time. There are three different models to explain the role of hydrogen dilution in the formation of $\mu \mathrm{c}-\mathrm{Si}: \mathrm{H}$ materials $[21,22]$. In the surface reaction models, it is important that the substrate surface is covered by hydrogen, on which film precursors diffuse more easily. In the growth zone models, the chemical annealing effect can provide energy for crystallization formation. Beyond that, since the deposition time for the high hydrogen dilution sample is longer, the in situ annealing effect can be another factor that promotes the crystallization of sample R999. Furthermore, it is noticed that there is an obvious downshift of crystal peak in Fig. 1(a). Sample R999 deposited at $R_{H}=999$ presents a strong crystalline peak near $295 \mathrm{~cm}^{-1}$. With a lower $R_{H}$, sample R499 presents a weaker crystalline peak and sample R249 only shows a tiny peak near $290 \mathrm{~cm}^{-1}$. It has been reported that Raman downshifts from $520 \mathrm{~cm}^{-1}$ in Si nanocrystals with the decrease in crystal size due to the confinement effects $[23,24]$. In $\mu \mathrm{c}-\mathrm{Ge}: \mathrm{H}$ films, the 
crystalline peak downshifts from $300 \mathrm{~cm}^{-1}$ for the same reason [25]. In Fig. 1(b) and (c), TEM shows the details of nanocrystals in sample R999 and sample R499. It is found that the crystal grain density and mean size of sample R499 are smaller than that of sample R999. For the mean size of crystal grains nearly $5 \mathrm{~nm}$, the downshift of Raman $\sim 300 \mathrm{~cm}^{-1}$ peak in sample R499 is stronger than that in sample R999.

Fig. 2 shows the deposition rate under different hydrogen dilution ratio. Comparing with the deposition rate at $R_{H}=499$, the deposition rate at $R_{H}=999$ has a sharp decline, and the initial deposition rate of $R_{H}=999(0.025 \mathrm{~nm} / \mathrm{s})$ is slightly higher than the average rate $(0.017 \mathrm{~nm} / \mathrm{s})$, for the slope of $R_{H}=999$ line reduces at latter half. The deposition rate is $0.07 \mathrm{~nm} / \mathrm{s}$ for the sample R199, while it is $0.025 \mathrm{~nm} / \mathrm{s}$ for the sample R999. In PECVD, a low deposition rate can cause great waste of reaction gas. In the manufacturing of semiconductor, at such a low deposition rate $\left(0.017 \mathrm{~nm} / \mathrm{s}, R_{H}=999\right)$, depositing a $100 \mathrm{~nm}$-thickness film needs 2 hours. Therefore, a deposition method, not only promoting the microstructure evolution but also keeping a high deposition rate, is required for manufacture.

\subsection{Effect of high plasma discharge power}

Plasma energy intensity is one of the key parameters for the deposition of $\mu \mathrm{c}-\mathrm{Ge}: \mathrm{H}$ films by PECVD [4]. By control of plasma discharge power, ideal plasma energy intensity is achieved. In addition, through discharge power control, quick adjustment of growth process is realized. Fig. 3 and Fig. 4 show two groups of different thickness samples prepared under $5 \mathrm{~W}$ and $35 \mathrm{~W}$ respectively. Table 2 lists the deposition parameters of these samples. In the process of adjusting time parameters, it is found that crystalline fraction and deposition rate increasing with discharge power increasing. The deposition rate of the $5 \mathrm{~W}$ samples closes to $0.015 \mathrm{~nm} / \mathrm{s}$, but it is about 
$0.058 \mathrm{~nm} / \mathrm{s}$ for the $35 \mathrm{~W}$ samples. In addition, in our PECVD system, when the discharge power exceeds 50W, plasma discharge appears unstable phenomenon, thus we chosen a stable condition in the range of $5-35 \mathrm{~W}$.

In Fig. 3(a), Raman scattering spectra shows the microstructure evolution that the crystalline fraction increases with the thickness increasing. The sample P051 and P052 are amorphous, while the sample P053, which crystalline fraction is $31 \%$, is microcrystalline. This demonstrates that the transition from amorphous to microcrystalline phase occurs in 17-29 nm thickness region. Furthermore, it illustrates the thickness of incubation layer is large than $17 \mathrm{~nm}$ for this group. In Fig. 3(b-e), the incubation and growth process of crystal grain is investigated by the AFM measurement [26]. In Fig. 3(b) and (c), AFM shows there are some grain structures on the surface of sample P051 and P052, while Raman measurement reflects no crystallization peak of these films. Thus these grain structures are amorphous, or the crystalline volume fraction of these grain structures is too small that the crystalline peak in Raman scattering spectra is covered by amorphous peak. Furthermore, Fig. 3(c), (d) and (e) illustrate the evolution process of the surface morphology from amorphous to microcrystalline. In this process, at first, nucleuses form on the surface of amorphous incubation layer, then it is followed by epitaxial-like growth to develop the crystallite [27]. In addition, according to the nucleation mechanism of $\mu \mathrm{c}-\mathrm{Si}: \mathrm{H}$ [28], the nucleuses of initial microcrystalline germanium crystal grains should be formed in the region of 17-29 nm.

In Fig. 4(a), Raman measurement shows the crystalline volume fractions of $35 \mathrm{~W}$ group, which deposited at a higher discharge power than the $5 \mathrm{~W}$ group. The sample $\mathrm{P} 351$ has a $X_{C}=7 \%$ and a thickness of $8 \mathrm{~nm}$, indicating the incubation layer thickness of $35 \mathrm{~W}$ samples is less than 8 $\mathrm{nm}$. The thinner incubation layer of $35 \mathrm{~W}$ samples indicates that a higher plasma energy density is 
benefit to crystal nucleus forming. In addition, with the same thickness, $35 \mathrm{~W}$ samples have a higher crystalline fraction than the $5 \mathrm{~W}$ samples. Therefore, at high hydrogen dilution conditions, a high energy density further reduces the thickness of incubation layer and increases the crystalline fraction. In Fig. 4(b), (c), (d) and (e), AFM results show the surface morphology of the $35 \mathrm{~W}$ samples. Comparing to the $5 \mathrm{~W}$ samples, the surface morphology of $35 \mathrm{~W}$ samples is rougher and the average grain size is smaller. Especially in the Fig. 4. (e), the sample P354 has a $X_{C}=77 \%$ and a thickness of $55 \mathrm{~nm}$, however, the average grain size $\sim 15 \mathrm{~nm}$ obvious smaller than that of sample P054 40 nm shown in Fig. 3. (e). Although the crystalline fraction of sample P054 only has $67 \%$, the grains are more compact and collision to each other. The sample P354 has smaller grain size than sample P054, but void structures appear between the grains in sample P354.

It was reported that the $\mu \mathrm{c}-\mathrm{Ge}: \mathrm{H}$ with high crystalline fraction tends to consist of compact grains surrounded by more or less open voids [29]. In the plasma process, ion damage is a possible cause of degradation of the film quality, and hydrogen dilution should lead to appearance of microvoid [27]. Furthermore, Matsui et al, reported that Ge dangling bonds at crystalline grain boundaries act as negatively charged acceptors and generate free holes in the films [30]. According to these, if the growth rate of crystal grain is too fast, at the high hydrogen dilution condition, a large amount of void structures will form and the electric properties of films will decrease. In addition, Yan B. et al, reported that though the $\mathrm{H}_{2}$ dilution profiling technique can partially control the structure homogeneity and improve the $\mu \mathrm{c}-\mathrm{Si}: \mathrm{H}$ solar cell efficiency [13]. Thus, when crystalline fraction increases to a certain degree, it is necessary that holding the growth of crystalline fraction to restrain the defect between crystal boundaries. Moreover, by the 
adjustment of the hydrogen dilution and the discharge power, the crystal nucleus formation can be controlled in the $\mu \mathrm{c}-\mathrm{Ge}: \mathrm{H}$ deposition process.

\subsection{Power gradient method}

In order to understand the mechanism of the crystal nucleation and the process of microstructure evolution, a group was prepared by the power gradient method at the high hydrogen dilution $R_{H}=999$. Table 3 shows the deposition parameters. According to the result of 5 $\mathrm{W}$ and $35 \mathrm{~W}$ power groups, at $35 \mathrm{~W}$ power, crystal nucleuses form faster. When power switches to $5 \mathrm{~W}$, crystals grow along the nucleuses to develop the crystallites. Thus through the power control, we can effectively control the deposition process. At the first stage, we deposited a $3 \mathrm{~nm}$ ultrathin film at $35 \mathrm{~W}$ discharge power to accelerate the formation of crystal nucleus. And then, we quickly turned down the power to $5 \mathrm{~W}$ in a short time $(<5 \mathrm{~s})$ and kept the plasma discharge continue. At 5 W discharge power, the film with crystal nucleuses followed deposition of different time to observe the microstructure evolution. In particular, the deposition rates of the stage 1 and 2 are $0.05 \mathrm{~nm} / \mathrm{s}$ and $0.015 \mathrm{~nm} / \mathrm{s}$, respectively, and close to the deposition rate shown in Table 2 .

In Fig. 5(a), Raman scattering spectra shows that all samples are microcrystalline because all samples have the $\sim 300 \mathrm{~cm}^{-1}$ peak. First of all, it demonstrates that the crystal nucleuses in the initial $3 \mathrm{~nm}$ layer have an intense effect on the amorphous to microcrystalline transition, otherwise the crystalline fractions of this group will approximate to that of the $5 \mathrm{~W}$ group. Furthermore, compared with the $35 \mathrm{~W}$ and $5 \mathrm{~W}$ groups, it is found that the group prepared by power gradient method has a higher crystalline fraction at the same thickness. In Fig. 4(f), the XRD of P345 and G4 indicates the films are microcrystalline, and they have the preferred orientation of 220 [31]. But in the line of sample P353 and G3, there is no obvious crystal peak. It should be the reason that the film is too 
thin, and the information of crystal grains cannot be collected effectively. It also means that when the thickness of film less than $30 \mathrm{~nm}$, Raman should be a good method to explore the crystallinity. Fig. 5(d) shows the relationship between crystalline fraction and film thickness. Using the power gradient method, although the discharge power kept at $5 \mathrm{~W}$ for most of the deposition time, samples have higher crystalline fraction than that of the $35 \mathrm{~W}$ and $5 \mathrm{~W}$ samples. In the $5 \mathrm{~W}$ group, it is also noticed that, from $17 \mathrm{~nm}$ to $29 \mathrm{~nm}$, a region of $12 \mathrm{~nm}$, the crystalline fraction increased from 0 to $31 \%$. Although the deposition rate of $5 \mathrm{~W}$ group only has $0.015 \mathrm{~nm} / \mathrm{s}$, the crystalline fraction has a quick increase in this region. It means that once the nucleus appears, the crystalline fraction rapidly increases. Therefore, in the power gradient method, crystal nucleuses rapidly form at a high discharge power $(35 \mathrm{~W})$, and the evolution from amorphous to microcrystalline is accelerated at a lower discharge power $(5 \mathrm{~W})$.

Fig. 5(b) and (c) show the surface morphology of sample G2 and sample G4. It is found that compared with the sample P054 in $5 \mathrm{~W}$ group, sample G4 has a smaller average grain size $\sim 20 \mathrm{~nm}$. However, compared with the sample P354 in $35 \mathrm{~W}$ group, sample G4 is more compact and has a smaller roughness. This indicates that the nucleuses in the initial $35 \mathrm{~W}$ layer of the power gradient method have a significant impact on the following deposition process at $5 \mathrm{~W}$ power. In addition, the nucleuses formed at $35 \mathrm{~W}$ power even affects the grain size in the $5 \mathrm{~W}$ layer. The top layer is deposited at $5 \mathrm{~W}$ discharge power, whereas the average grain size closes to the samples of $35 \mathrm{~W}$ group. It is attributed to the epitaxial-like growth in the crystal growth [27]. For the crystallites growth along the crystal nucleuses, crystal nucleus also affects the average grain size. Finally, the power gradient method reduces the incubation layer thickness and restrains the crystalline fraction. Thus the formation of crystal nucleuses is a key factor for the initial deposition process of 
$\mu c-G e: H$ thin films.

Fig. 6. (a) shows the TFT structure with a $\mu \mathrm{c}-\mathrm{Ge}: \mathrm{H}$ channel $(400 \mu \mathrm{m}$ width and $200 \mu \mathrm{m}$ length) and a $\mathrm{SiO}_{2}(270 \mathrm{~nm})$ gate dielectric layer as previously reported elsewhere [32]. Fig.6. (b)(c)(d) show the transfer characteristics of TFTs with $\mu \mathrm{c}-\mathrm{Ge}: \mathrm{H}$ channel layers deposited under different power conditions. All TFTs operate in the linear regime and appear n-type transfer characteristics [32-35]. The mobility $\mu_{\mathrm{e}}$ is extracted using the following equation [34]:

$$
\mu_{e}=\frac{1}{C_{i} V_{d}} \times \frac{L}{W} \times \frac{\delta I}{\delta V_{g}}
$$

in which $\mathrm{I}$ is the drain current, $\mathrm{V}_{\mathrm{g}}$ is the gate voltage, $\mathrm{L}$ is the channel length, $\mathrm{W}$ is the channel width and $\mathrm{C}_{\mathrm{i}}$ is the gate insulator capacitance.

At first, the TFT with the power gradient method in Fig.6 (d) has the highest mobility of 0.16 $\mathrm{cm}^{2} \mathrm{~s}^{-1} \mathrm{v}^{-1}$ among the three samples. The mobility of $35 \mathrm{~W}$ TFT is $0.099 \mathrm{~cm}^{2} \mathrm{~s}^{-1} \mathrm{v}^{-1}$ while the mobility of $5 \mathrm{~W}$ TFT is $0.0056 \mathrm{~cm}^{2} \mathrm{~s}^{-1} \mathrm{v}^{-1}$. With the same device structure and channel layer thickness $(20 \mathrm{~nm})$, the different mobility of TFTs should be related to the crystal fraction and the crystal quality of the $\mu \mathrm{c}-\mathrm{Ge}: \mathrm{H}$ channel layer. The channel layer of $5 \mathrm{~W}$ TFT is no-crystal material, with a high carrier trapping and recombination rate, which leads to a low carrier mobility. The channel layer of 35 W TFT has higher crystal fraction thus the carrier transport ability is improved. For the power gradient method TFT, the improved performance is not only caused by the higher crystal fraction but also caused by the distribution and size of crystal grain is more homogeneous. Finally, all these results suggest that the quality of $\mu \mathrm{c}-\mathrm{Ge}: \mathrm{H}$ material is controlled by crystal fraction and crystal structure simultaneously.

\section{Conclusion}


The initial deposition process of $\mu \mathrm{c}-\mathrm{Ge}: \mathrm{H}$ thin films prepared by PECVD has been studied. The high hydrogen dilution and the high discharge power methods effectively promote the microstructure evolution from amorphous to microcrystalline. In addition, the decrease of deposition rate caused by high hydrogen dilution is compensated by using a higher discharge power, but the rapidly crystal growth leads to smaller average grain size and more void structures in the film. The power gradient method is proposed to understand the mechanism of nucleation and the process of microstructure evolution. It is found that the nucleuses appeared in the initial layer have a great effect on the following deposition process. Especially, the average grain size is at large extent changed for the nucleuses formed at different condition. By the power gradient method, a high crystalline fraction $\mu \mathrm{c}-\mathrm{Ge}: \mathrm{H}$ film with ultrathin incubation layer $(<6 \mathrm{~nm})$ was deposited at high hydrogen dilution $\left(R_{H}=999\right)$. The forming of crystal nucleuses is promoted at high discharge power, and crystallinity is hold to achieve a homogeneous distribution of the crystal grains at low power. Furthermore, the transfer characteristic of TFT devices shows the power gradient method effectively promotes the electrical properties. As a result, a high quality $\mu \mathrm{c}-\mathrm{Ge}: \mathrm{H}$ film, $38 \mathrm{~nm}, X_{C}=48 \%$, with an incubation layer less than $6 \mathrm{~nm}$ was obtained.

\section{Acknowledgement}

This work was supported by the National Natural Science Foundation of China (No. 61404073) and the National Science Foundation of China (Grant No. 61377031).

\section{References}

[1] W.A. Turner, S.J. Jones, D. Pang, B.F. Bateman, J.H. Chen, Y.M. Li, F.C. Marques, A.E. Wetsel, P. Wickboldt, W. Paul, J. Bodart, R.E. Norberg, I.E. Zawawi, M.L. Theye, Structural, optical, and electrical characterization of improved amorphous hydrogenated germanium, J. 
Appl. Phys. 67 (1990) 7430-7438.

[2] W.B. Jordan, S. Wagner, Effects of deposition temperature and film thickness on the structural, electrical, and optical properties of germanium thin films, Mat. Res. Soc. Symp. Proc. 715 (2002) 1821-1826.

[3] M. Krause, H. Stiebig, R. Carius, H. Wagner, Microcrystalline germanium photodetectors, Mat. Res. Soc. Symp. Proc. 664 (2001) 2651-2656.

[4] E.V. Johnson, P. Roca i Cabarrocas, High quality a-Ge:H films and devices through enhanced plasma chemistry, Mater. Res. Soc. Symp. Proc. 989 (2007).

[5] J. Koh, A.S. Ferlauto, P.I. Rovira, C.R. Wronski, R.W. Collins, Evolutionary phase diagrams for plasma-enhanced chemical vapor deposition of silicon thin films from hydrogen-diluted silane, Appl. Phys. Lett. 75 (1999) 2286-2288.

[6] E. Vallat-Sauvain, U. Kroll, J. Meier, A. Shah, J. Pohl, Evolution of the microstructure in microcrystalline silicon prepared by very high frequency glow-discharge using hydrogen dilution, J. Appl. Phys. 87 (2000) 3137-3142.

[7] M.N. van den Donker, B. Rech, F. Finger, L. Houben, W.M.M. Kessels, M.C.M. van de Sanden, Deposition of highly efficient microcrystalline silicon solar cells under conditions of low $\mathrm{H}_{2}$ dilution: the role of the transient depletion induced incubation layer, Prog. Photovolt: Res. Appl. 15 (2007) 291-301.

[8] H. Fujiwara, Y. Toyoshima, M. Kondo, A. Matsuda, Structural study of initial layer for $\mu c-S i: H$ growth using real time in situ spectroscopic ellipsometry and infrared spectroscopy, J. Non-Cryst. Solids 266-269 (2000) 38-42.

[9] I. Petrov, P.B. Barna, L. Hultman, J.E. Greene, Microstructural evolution during film growth, 
J. Vac. Sci. Technol. A 21 (2003) 117-128.

[10] Y. Okamoto, K. Makihara, S. Higashi, S. Miyazaki, Formation of microcrystalline germanium ( $\mu \mathrm{c}-\mathrm{Ge}: \mathrm{H})$ films from inductively coupled plasma CVD, Appl. Surf. Sci. 244 (2005) $12-15$.

[11] C. Godet, P. Roca i Cabarrocas, S.C. Gujrathi, P. A. Burret, Hydrogen profiling by elastic recoil detection in microcrystalline germanium thin films, J. Vac. Sci. Technol. A 10 (1992) $3517-3521$.

[12] J.K. Rath, Low temperature polycrystalline silicon: a review on deposition, physical properties and solar cell applications, Sol. Energy Mater. Sol. Cells 76 (2003) 431-487.

[13] B. Yan, G. Yue, J. Yang, S. Guha, D.L. Williamson, D. Han, C.S. Jiang, Hydrogen dilution profiling for hydrogenated microcrystalline silicon solar cells, Appl. Phys. Lett. 85 (2004) 1955-1957.

[14] P.R. Poulsen, M. Wang, J. Xu, W. Li, K. Chen, G. Wang, D. Feng, Role of hydrogen surface coverage during anodic plasma deposition of hydrogenated nanocrystalline germanium, J. Appl. Phys. 84 (1998) 3386-3391.

[15] H. Yue, A. Wu, X. Zhang, T. Li, New two-step growth of microcrystalline silicon thin films without incubation layer, J. Cryst. Growth 322 (2011) 1-5.

[16] D. Das, M. Jana, Hydrogen plasma induced microcrystallization in layer-by-layer growth scheme, Sol. Energy Mater. Sol. Cells 81 (2004) 169-81.

[17] M. Kang, J. Kim, Y. Koo, T. Lim, I. Oh, B. Jeon, I. Jung, C. An, Characteristics of a-Si:H films prepared by ECR CVD as a function of the H2/SiH4, Mater. Chem. Phys. 51 (1997) $152-156$. 
[18] D. Han, G. Yue, J.D. Lorentzen, J. Lin, H. Habuchi, Q. Wang, Optical and electronic properties of microcrystalline silicon as a function of microcrystallinity, J. Appl. Phys. 87 (2000) 1882-1888.

[19] P. Klement, C. Feser, B. Hanke, K.V. Maydell, C. Agert, Correlation between optical emission spectroscopy of hydrogen/germane plasma and the Raman crystallinity factor of germanium layers, Appl. Phys. Lett. 102 (2013) 152109.

[20] C. Droz, E. Vallat-Sauvain, J. Bailat, L. Feitknecht, J. Meier, A. Shah, Relationship between Raman crystallinity and open-circuit voltage in microcrystalline silicon solar cells, Sol. Energy Mater. Sol. Cells 81 (2004) 61-71.

[21] K. Saitoh, M. Kondo, M. Fukawa, T. Nishimiya, A. Matsuda, W. Futako, I. Shimizu, Role of the hydrogen plasma treatment in layer-by-layer deposition of microcrystalline silicon, Appl. Phys. Lett. 71 (1997) 3403-3405.

[22] A. Fontcuberta i Morral, J. Bertomeu, P. Roca i Cabarrocas, The role of hydrogen in the formation of microcrystalline silicon, Mater. Sci. Eng. B 69-70 (2000) 559-563.

[23] C. Ossadnik, S. Veprek, I. Gregora, Applicability of Raman scattering for the characterization of nanocrystalline silicon, Thin Solid Films 337 (1999) 148-151.

[24] C. Smit, R.A.C.M.M. van Swaaij, H. Donker, A.M.H.N. Petit, W.M.M. Kessels, M.C.M. van de Sanden, Determining the material structure of microcrystalline silicon from Raman spectra, J. Appl. Phys. 94 (2003) 3582-3588.

[25] D.R. dos Santos, I.L. Torriani, Crystallite size determination in $\mu c-G e$ films by X-ray diffraction and Raman line profile analysis, Solid State Commun. 85 (1993) 307-310.

[26] W.B. Jordan, E.D. Carlson, T.R. Johnson, S. Wagner, Structural evolution of nanocrystalline 
germanium thin films with film thickness and substrate temperature, Mat. Res. Soc. Symp. Proc. 762 (2003) 651-655.

[27] M. Kondo, H. Fujiwara, A. Matsuda, Fundamental aspects of low-temperature growth of microcrystalline silicon, Thin Solid Films 430 (2003) 130-134.

[28] H. Fujiwara, M. Kondo, A. Matsuda, Nucleation mechanism of microcrystalline silicon from the amorphous phase, J. Non-Cryst. Solids 338-340 (2004) 97-101.

[29] W. Beyer, F. Einsele, M. Kondo, T. Matsui, F. Pennartz, Microstructure effects in amorphous and microcrystalline Ge:H films, Mater. Res. Soc. Symp. Proc. 1245 (2010).

[30] T. Matsui, C.W. Chang, K. Mizuno, Y. Takeuchi, M. Kondo, Compensation of native defect acceptors in microcrystalline $\mathrm{Ge}$ and $\mathrm{Si}_{1-\mathrm{x}} \mathrm{Ge}_{\mathrm{x}}$ thin films by oxygen incorporation: electrical properties and solar cell performance, Jpn. J. Appl. Phys. 51 (2012) 091302.

[31] D.R. dos Santos, I.L. Torriani, Crystallite size determination in $\mu c-G e$ films by $\mathrm{X}$-ray diffraction and Raman line profile analysis, Solid State Commun. 85 (1993) 307-310.

[32] Y. Wu, J. Li, J. Xu, Y. Du, L. Huang, J. Ni, H. Cai, J. Zhang, Organic-inorganic hybrid $\mathrm{CH}_{3} \mathrm{NH}_{3} \mathrm{PbI}_{3}$ perovskite materials as channels in thin-film field-effect transistors, RSC Adv. 6 (2016) 16243-16249.

[33] Z.C. Holman, C.Y. Liu, U.R. Kortshagen, Germanium and silicon nanocrystal thin-film field-effect transistors from solution, Nano Let t. 10 (2010) 2661-2666.

[34] P. Stadler, B.R. Sutherland, Y. Ren, Z. Ning, A. Simchi, S.M. Thon, S. Hoogland, E.H. Sargent, Joint mapping of mobility and trap density in colloidal quantum dot solids, ACS Nano 7 (2013) 5757-5762.

[35] S.D. Brotherton, Polycrystalline silicon thin film transistors, Semicond. Sci. Technol. 10 
(1995) 721-738. 
Table of tables and figures:

Table 1 Deposition parameters and crystalline fractions of $\mu \mathrm{c}-\mathrm{Ge}: \mathrm{H}$ samples.

Table 2 Deposition parameters of the $5 \mathrm{~W}, 35 \mathrm{~W}$ and $15 \mathrm{~W}$ discharge power samples.

Fig. 1. Raman and TEM measurements of $\mu \mathrm{c}-\mathrm{Ge}: \mathrm{H}$ prepared under different hydrogen dilution ratios. All these samples have a similar thickness about $25 \mathrm{~nm}$. (a) Raman spectra. The signal intensities are normalized to the maximum values. Dashed lines represent the peak of crystalline Ge at $300 \mathrm{~cm}^{-1}$ and amorphous Ge at $275 \mathrm{~cm}^{-1}$. (b), (c) TEM images of sample R999 and R499 (5 $\mathrm{nm}$ scale). The Ge crystal regions are surrounded by the white dotted circles.

Fig. 2. The relationship between thickness and deposition time. At $R_{H}=999$, deposition rate significantly decreases. The inset shows the thickness-time relationship of sample R199, R249, R499 and R999.

Fig. 3. (a) The Raman spectrum of $5 \mathrm{~W}$ samples. (b), (c), (d) and (e) AFM images of sample P051, P052, P053 and P054 (1 $\mu \mathrm{m}$ scale).

Fig. 4. (a) The Raman spectrum of $35 \mathrm{~W}$ samples. (b), (c), (d) and (e) AFM images of sample P351, P352, P353 and P354 (1 $\mu \mathrm{m}$ scale). (f) X-ray Diffraction of $35 \mathrm{w}$ and power gradient samples.

Fig. 5. (a) The Raman spectrum shows the crystal fraction. (b) AFM images of sample G2 with a thickness of $10 \mathrm{~nm}$. (c) AFM images of sample G4 with a thickness of $38 \mathrm{~nm}$. (d) The relationship between thickness and crystalline fraction at high hydrogen dilution $R_{H}=999$. The arrow marks show the crystalline fraction increase of the power gradient samples, compared with the $5 \mathrm{~W}$ group.

Fig. 6. (a) TFT structure with Ge:H channel layer. (b)(c)(d) I-V transfer characteristic of TFTs 
with different deposition power. 

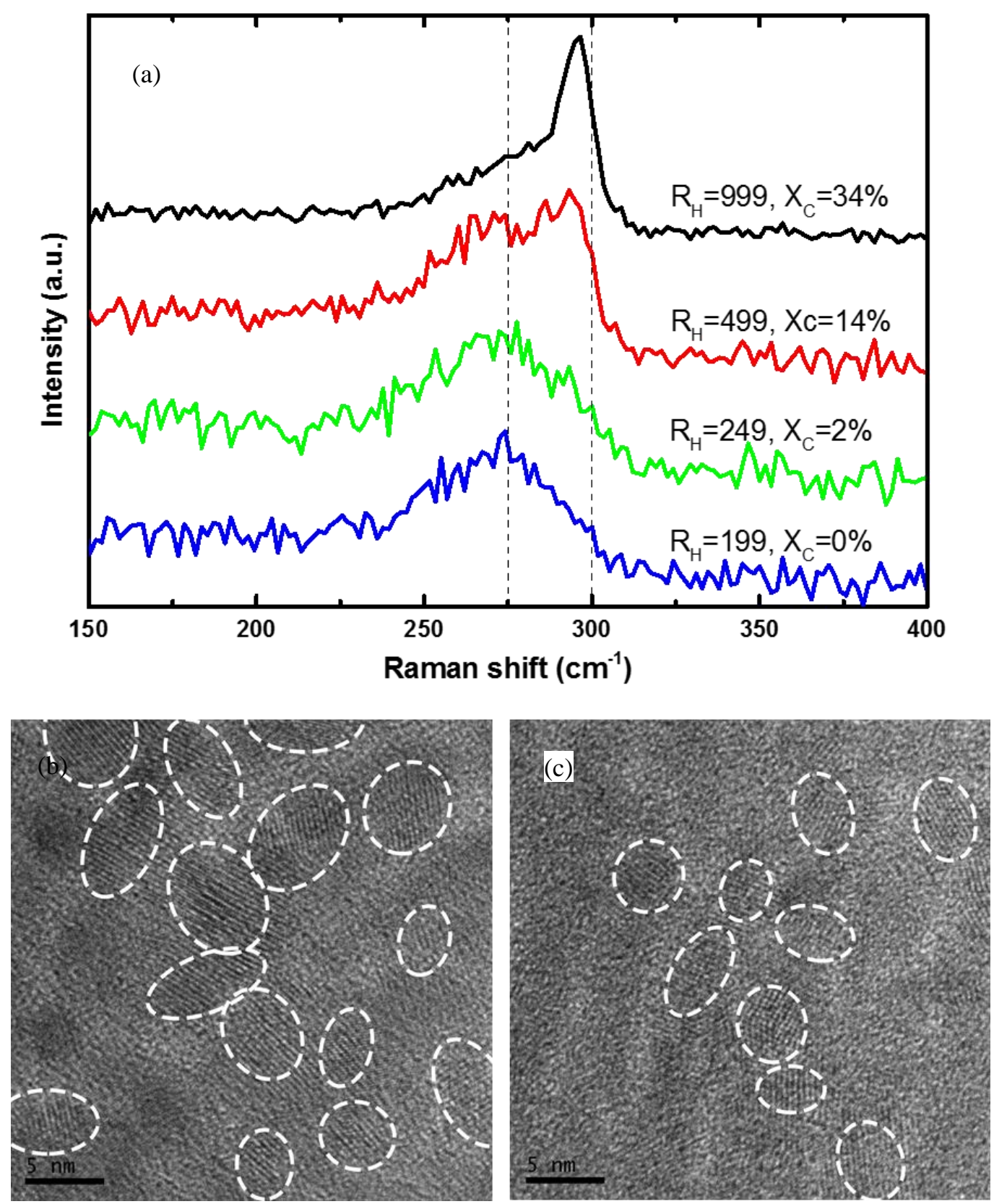

Fig. 1. Raman and TEM measurements of $\mu \mathrm{c}-\mathrm{Ge}: \mathrm{H}$ prepared under different hydrogen dilution ratios. All these samples have a similar thickness about $25 \mathrm{~nm}$. (a) Raman spectra. The signal intensities are normalized to the maximum values. Dashed lines represent the peak of crystalline Ge at $300 \mathrm{~cm}^{-1}$ and amorphous Ge at $275 \mathrm{~cm}^{-1}$. (b), (c) TEM images of sample R999 and R499 (5 nm scale). The Ge crystal regions are surrounded by the white dotted circles. 


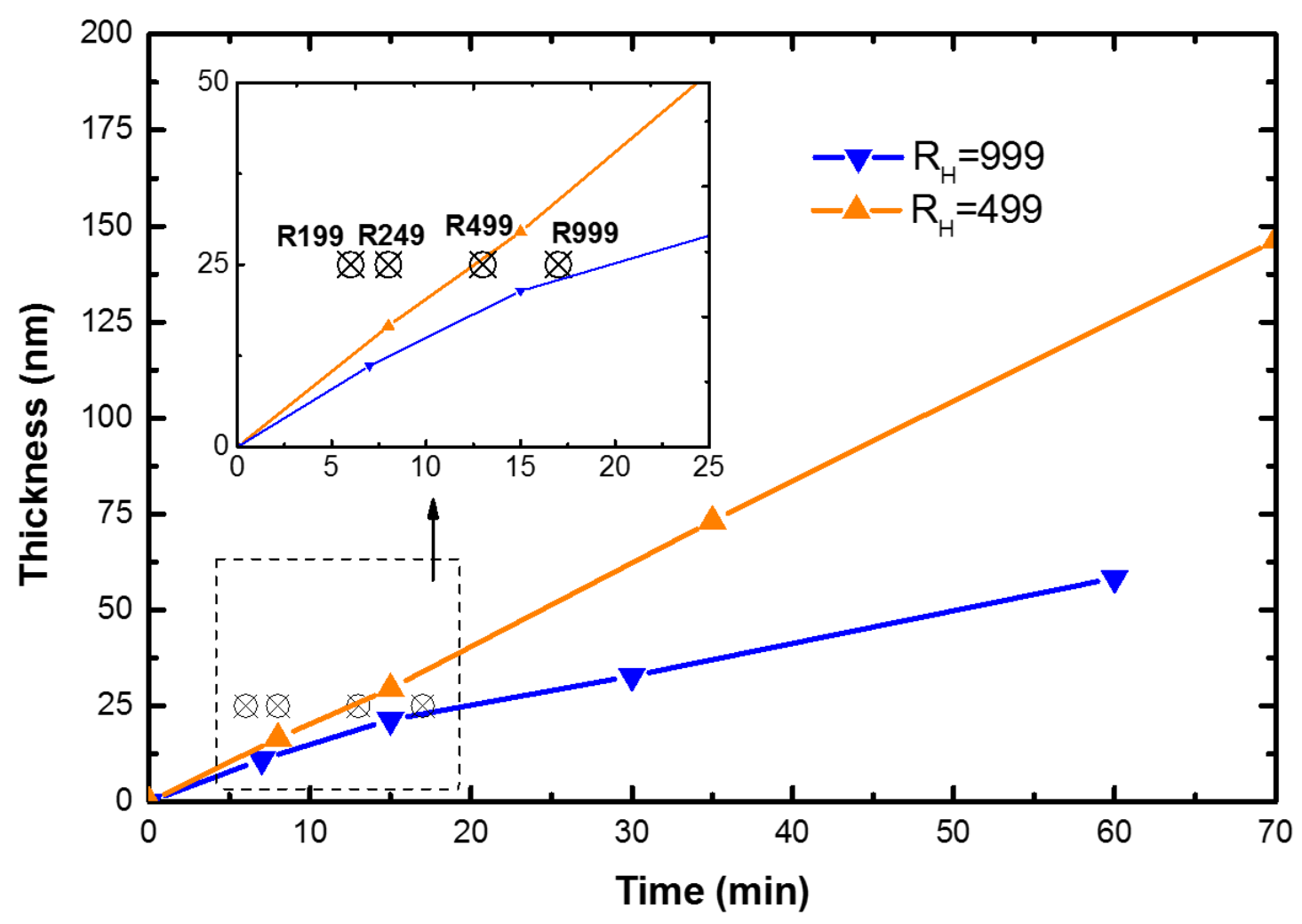

Fig. 2. The relationship between thickness and deposition time. At $R_{H}=999$, deposition rate significantly decreases. The inset shows the thickness-time relationship of sample R199, R249, R499 and R999. 

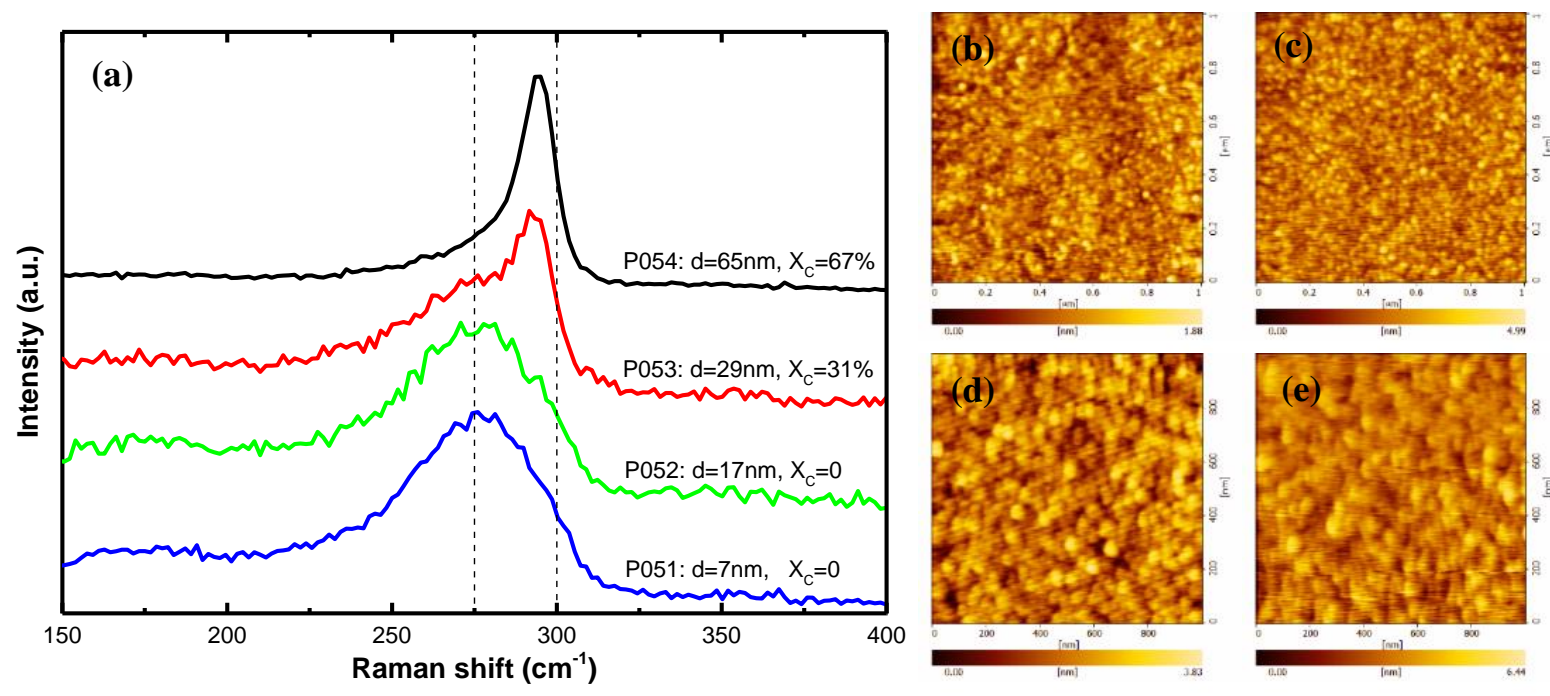

Fig. 3. (a) The Raman spectrum of $5 \mathrm{~W}$ samples. (b), (c), (d) and (e) AFM images of sample P051, P052, P053 and P054 (1 $\mu \mathrm{m}$ scale). 

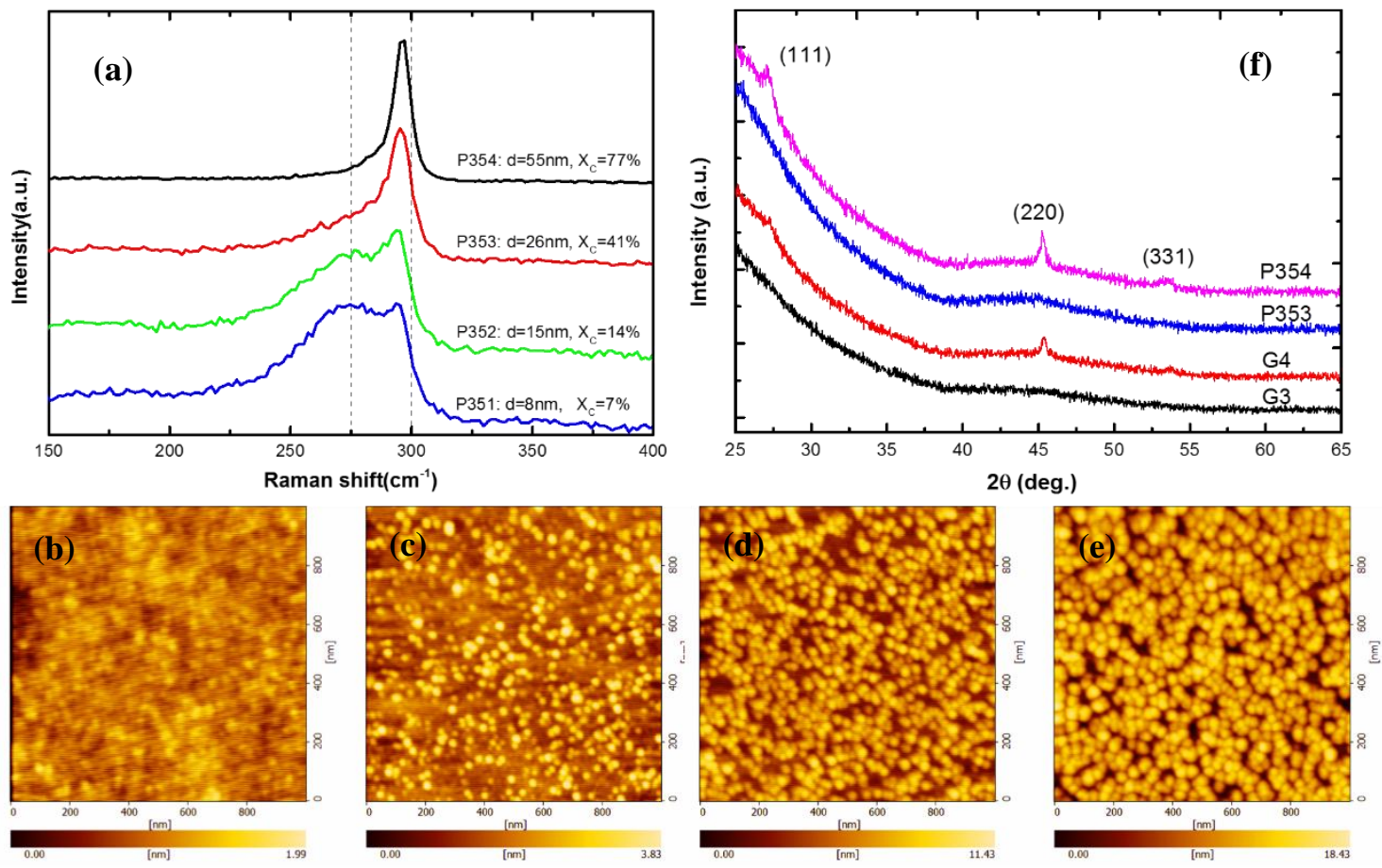

Fig. 4. (a) The Raman spectrum of $35 \mathrm{~W}$ samples. (b), (c), (d) and (e) AFM images of sample P351, P352, P353 and P354 (1 $\mu \mathrm{m}$ scale). (f) X-ray Diffraction of 35w and power gradient samples. 

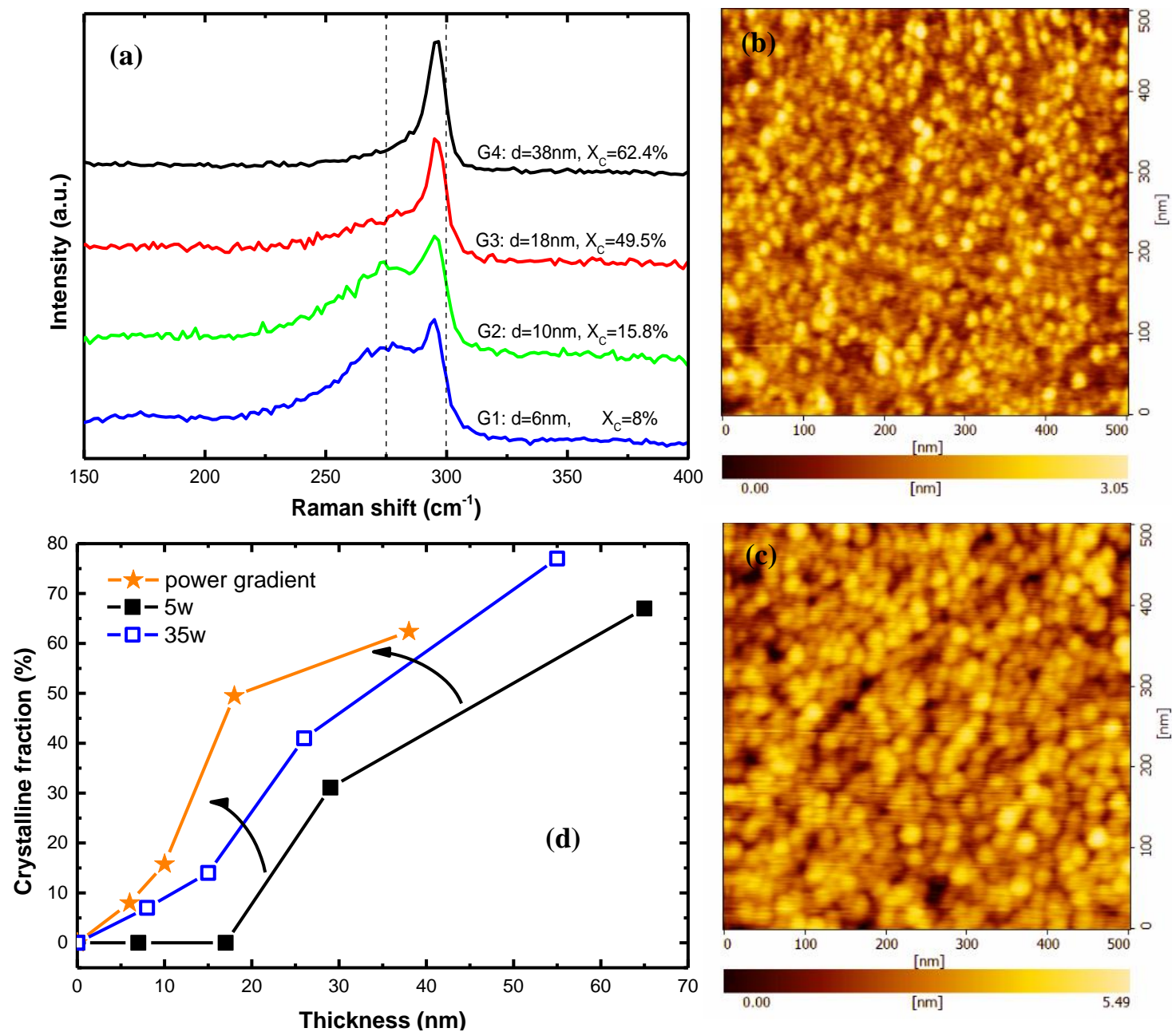

Fig. 5. (a) The Raman spectrum shows the crystal fraction. (b) AFM images of sample G2 with a thickness of $10 \mathrm{~nm}$. (c) AFM images of sample G4 with a thickness of $38 \mathrm{~nm}$. (d) The relationship between thickness and crystalline fraction at high hydrogen dilution $R_{H}=999$. The arrow marks show the crystalline fraction increase of the power gradient samples, compared with the $5 \mathrm{~W}$ group. 
(a) TFT structure

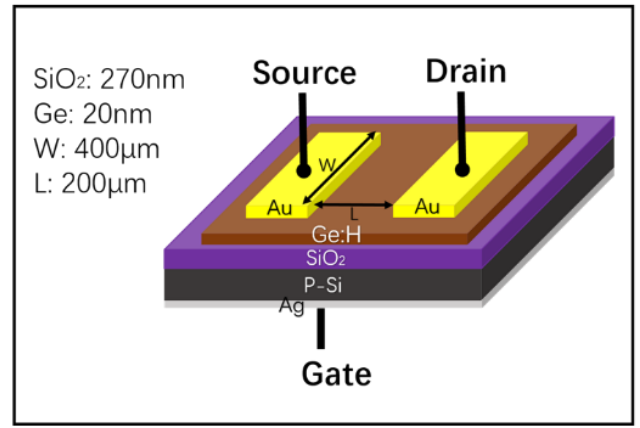

(c)

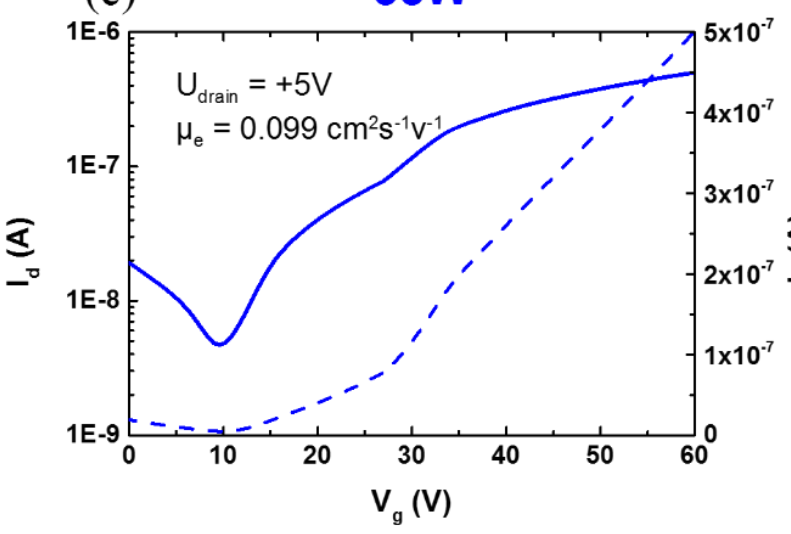

(b)

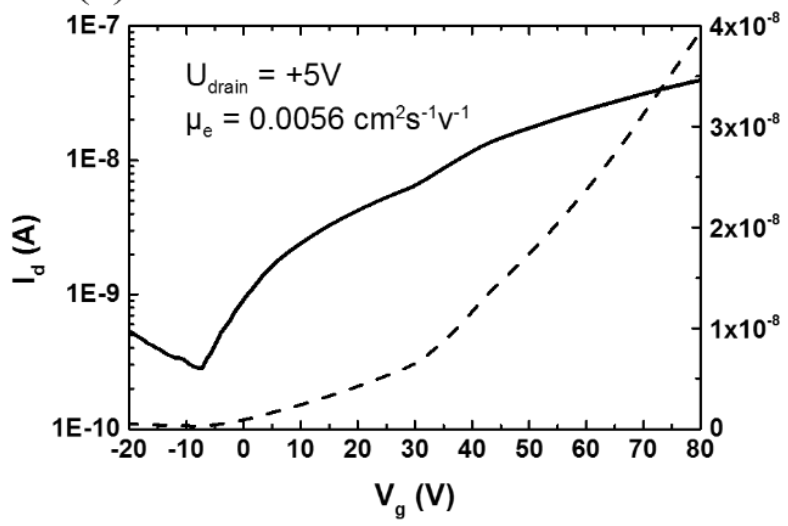

(d) Power Gradient Method

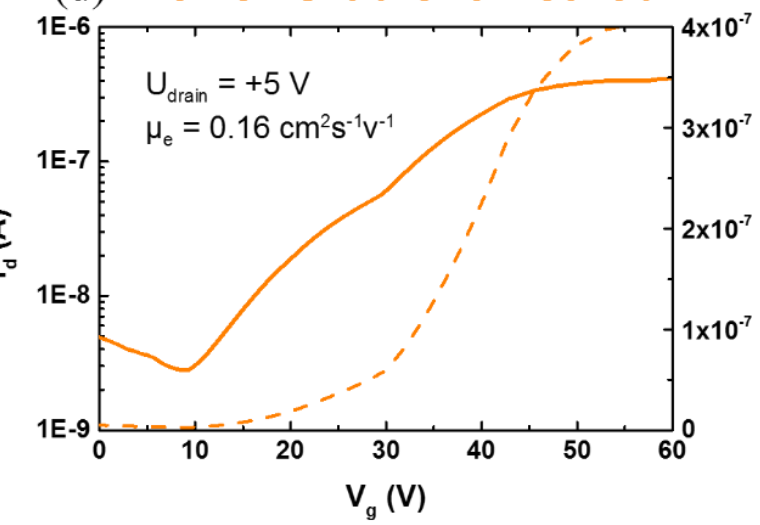

Fig. 6. (a) TFT structure with Ge:H channel layer. (b)(c)(d) I-V transfer characteristic of TFTs with different deposition power. 
Table 1 Deposition parameters and crystalline fractions of $\mu \mathrm{c}-\mathrm{Ge}: \mathrm{H}$ samples.

\begin{tabular}{cccccc}
\hline Sample & $\boldsymbol{R}_{\boldsymbol{H}}$ & $\begin{array}{c}\text { Power } \\
(\mathbf{w})\end{array}$ & $\begin{array}{c}\text { Time } \\
(\mathbf{m i n})\end{array}$ & $\begin{array}{c}\text { Thickness } \\
(\mathbf{n m})\end{array}$ & $\begin{array}{c}\boldsymbol{X}_{\boldsymbol{C}} \\
(\boldsymbol{\%})\end{array}$ \\
\hline R999 & 999 & 15 & 17 & 25 & 34 \\
R499 & 499 & 15 & 13 & 25 & 14 \\
R249 & 249 & 15 & 8 & 25 & 2 \\
R199 & 199 & 15 & 6 & 25 & 0 \\
\hline
\end{tabular}

Table 2 Deposition parameters of the $5 \mathrm{~W}, 35 \mathrm{~W}$ and $15 \mathrm{~W}$ discharge power samples.

\begin{tabular}{cccc}
\hline Sample & $\boldsymbol{R}_{\boldsymbol{H}}$ & Power $(\mathbf{w})$ & $\begin{array}{c}\text { Average deposition rate } \\
(\mathbf{n m} / \mathbf{s})\end{array}$ \\
\hline P05(1-4) & 999 & 5 & 0.015 \\
P35(1-4) & 999 & 35 & 0.058 \\
R999 & 999 & 15 & 0.017 \\
\hline
\end{tabular}

Table 3 Deposition parameters of $\mu \mathrm{c}-\mathrm{Ge}: \mathrm{H}$ samples.

\begin{tabular}{ccccccc}
\hline Stage & Sample & $\boldsymbol{R}_{\boldsymbol{H}}$ & $\begin{array}{c}\text { Power } \\
(\mathbf{w})\end{array}$ & $\begin{array}{c}\text { Total Time } \\
(\mathbf{m i n})\end{array}$ & $\begin{array}{c}\text { Total Thickness } \\
(\mathbf{n m})\end{array}$ & $\begin{array}{c}\boldsymbol{X}_{\boldsymbol{C}} \\
(\boldsymbol{\%})\end{array}$ \\
\hline $\mathbf{1}$ & G1-4 & 999 & 35 & 1 & 3 & - \\
\hline \multirow{2}{*}{$\mathbf{2}$} & G1 & 999 & 5 & 5 & 6 & 8 \\
& G2 & 999 & 5 & 10 & 10 & 15.8 \\
& G3 & 999 & 5 & 20 & 18 & 49.5 \\
& G4 & 999 & 5 & 40 & 38 & 62.4 \\
\hline
\end{tabular}

